\title{
Implicaciones educativas del conocimiento antropológico
}

DOI: https://doi.org/10.18046/recs.i33.4170

\author{
Educational Implications \\ of Anthropological Knowledge
}

Juan Camilo Perdomo-Marín**

Universidad de Caldas (Manizales, Colombia)

${ }^{*}$ El presente escrito está basado en el trabajo final del Diplomado en Docencia Universitaria de la Universidad de Caldas (2019-2). Artículo de reflexión recibido el 13.07.20 y aceptado el 03.01.2021.

** Antropólogo egresado de la Universidad de Caldas (Colombia) y docente de la misma institución. Correo electrónico: juancaperdo@hotmail.com ORCID: https://orcid.org/0000-0003-2714-455X 


\section{Cómo citar/How to cite}

Perdomo-Marín, Juan Camilo (2021). Implicaciones educativas del conocimiento antropológico. Revista CS, 33, 41-74. https://doi.org/10.18046/recs.i33.4170 


\section{Resumen}

Este artículo reflexiona sobre las dinámicas, problemáticas y oportunidades de la educación universitaria en antropología. Su objetivo es identificar cómo dicha disciplina entiende los procesos de aprendizaje, sus nuevas apuestas experimentales de enseñanza y los múltiples desafíos que afrontan sus docentes. Lo anterior permitirá concluir que la antropología tiene el potencial de integrar la comprensión del mundo social en sus estrategias de enseñanza.

\section{PALABRAS CLAVE:}

antropología, educación universitaria, pedagogía, habilidades, Colombia

This paper reflects on the dynamics, problems, and opportunities of tertiary education in anthropology. The objective is to identify how this discipline understands the learning process, its new experimental teaching goals and the multiple challenges its teachers face. This will allow to conclude that anthropology has the potential to integrate the understanding of the social world within its teaching strategies.

\section{KEYWORDS:}

Anthropology, Tertiary Education, Pedagogy, Skill, Colombia 



\section{Introducción}

En Colombia, no existen reflexiones directas sobre las dinámicas de la enseñanza de la antropología en las universidades, aunque es posible encontrar diversas genealogías sobre su historia en el país, enfocadas en el surgimiento de sus programas y sus legados investigativos y políticos; e investigaciones emergentes sobre la antropología de la educación, basadas en etnografías de procesos educativos en escuelas rurales. Solamente aparecen comentarios secundarios, por ejemplo, el de Jimeno y Arias (2011: 38), quienes exponen que la formación en el país

aún descansa demasiado en la pedagogía de la cátedra magistral que supone un alumno receptáculo de contenidos que "llena" el profesor, con mínima intervención del estudiante. La pedagogía basada en la cátedra magistral es muy apreciada en nuestro medio; aún el parámetro de calificación de un "buen” docente es aquel que ofrece grandes y eruditas exposiciones. Esto muy a pesar de las reformas que buscan modificarla en el conjunto de universidades.

La pedagogía no ha sido un tema de gran interés en las universidades por diversos motivos. Los debates sobre la educación se han centrado en el estudio de la formación en escuelas y colegios; además, escudándose en la libertad de cátedra, muchos docentes universitarios han evitado la reflexión colectiva y autocrítica sobre sus estrategias de enseñanza. Por este motivo, como evidencia el testimonio citado, en el país todavía persiste una concepción pasiva del estudiante.

Para Blum (2019), la pedagogía no ha estado entre los temas más abordados de la disciplina debido a que los antropólogos, al estudiar sus propias dinámicas de enseñanza, pueden sentirse intimidados al estar expuestos ante la evaluación de sus instituciones y colegas. También a que las estrategias de enseñanza se dan por obvias y, por lo tanto, no se consideran un objeto de estudio relevante. A su vez, porque la evaluación de la calidad académica se ha centrado en la producción intelectual, no en el desempeño pedagógico. Sumado a lo anterior, hay una falta de interés por parte de los docentes en explorar los debates teóricos sobre la educación debido a que se encuentran por fuera de sus campos de investigación.

Ahora bien, la discusión sobre la pedagogía en antropología cobra una mayor relevancia por tres motivos. Primero, las nuevas dinámicas universitarias, donde existe una mayor presión institucional por capacitar a los docentes en pedagogía para mejorar la calidad académica de sus programas y así asegurar su acreditación, pero esta búsqueda de cambio no solo es externa, pues la renovación generacional de las plantas profesorales ha permitido que los programas integren nuevos docentes que critican los modelos pedagógicos en los que fueron formados y comienzan a explorar estrategias alternativas de enseñanza y evaluación. 
En segundo lugar, están los cambios en la proyección laboral de la disciplina. El enfoque multicultural de la Constitución de 1991 creó una amplia demanda institucional de antropólogos no especializados para los pocos egresados de las décadas anteriores. Actualmente, hay un desbalance entre las necesidades institucionales de profesionales de las ciencias sociales y la amplia cantidad de egresados. Aun así, en los últimos años han surgido nuevos campos de trabajo, pero estos requieren de habilidades específicas para asegurar la inserción laboral, como conocimientos en torno al género, el medioambiente y la educación, los cuales no siempre se ofrecen en los programas de pregrado.

Tercero, las redes de conocimiento generadas por el internet evidencian que la producción científica de la antropología ha aumentado exponencialmente en los últimos años. Ahora los estudiantes acceden rápidamente a una amplia cantidad de información, a partir de la cual pueden evaluar la calidad académica de sus programas y docentes. En contraste con las décadas anteriores, las nuevas herramientas tecnológicas han conducido a que las nuevas generaciones de alumnos posean mayores requerimientos de actualización teórica y planificación pedagógica, y a que sean mucho más conscientes sobre las deficiencias de su formación. A su vez, debido las redes virtuales, ahora los docentes pueden acceder a un ambiente pedagógico altamente estimulante que les permite conocer y comunicar prácticas educativas experimentales de todo el mundo.

A partir de la experiencia como estudiante y después como docente, conozco las problemáticas de la enseñanza de la antropología. Dado que los profesores piensan más en su contenido que en su forma, hay poco acercamiento a nuevas apuestas pedagógicas, lo cual ha limitado su capacidad de identificar y trabajar en las fortalezas y dificultades diferenciales de los estudiantes. Por consiguiente, es urgente que los directores académicos, los docentes y los estudiantes dialoguen crítica y propositivamente sobre las estrategias pedagógicas que requiere una formación integral en antropología. De otro modo, los programas universitarios continuarán limitando el desarrollo de las habilidades profesionales necesarias para ampliar las posibilidades de movilidad social y apertura intelectual de sus egresados.

Considerando lo expuesto, el presente escrito reflexionará sobre las dinámicas, las problemáticas y las oportunidades de la educación universitaria en antropología. El objetivo de este trabajo es identificar, primero, cómo esta disciplina entiende los procesos de aprendizaje en la vida cotidiana; segundo, sus nuevas apuestas experimentales de enseñanza; y finalmente, los múltiples desafíos que afrontan sus docentes. Lo anterior permitirá concluir que la antropología tiene el potencial de integrar la comprensión de la realidad en sus estrategias de enseñanza. 


\section{La educación desde la antropología}

\section{El aprendizaje como práctica de atención}

Los debates contemporáneos de la antropología sostienen que el conocimiento se elabora a partir de la participación del cuerpo en el medioambiente. Ingold (2000; 2003; 2018) afirma que la enseñanza no consiste en comunicar pasivamente información de una mente a otra, como si esta existiera enteramente antes de los actores. Ello se debe a que los significados no se encuentran predefinidos en palabras o símbolos esperando su replicación, sino que emergen en la interacción con el mundo. En otras palabras, en vez de anteceder la experiencia, el conocimiento surge, se modifica y se estabiliza por medio de las acciones.

Lo anterior implica que el aprendizaje se basa en el desarrollo de habilidades de atención. Ingold (2000) ejemplifica su argumento a través del caso del cazador experimentado, el cual no consultaría las imágenes mentales que tiene sobre el mundo, sino al mundo mismo. Antes de recurrir a representaciones culturales, el cazador aprende a leer diversos estímulos ambientales mediante la sensibilidad forjada en su cuerpo, por lo tanto,

lo que cada generación contribuye a la siguiente, entonces, no son reglas y esquemas de producción de un comportamiento adecuado, sino las condiciones específicas de desarrollo bajo las cuales los sucesores, creciendo en un mundo social, adquieren sus propias habilidades y disposiciones encarnadas. (Ingold, 2000: 387 )

Enseñar no es trasmitir información, sino crear un ambiente de aprendizaje para que el sujeto desarrolle habilidades de atención en torno a tareas específicas y surja el saber. Por consiguiente, la educación es un compromiso de todas las generaciones para elaborar "las condiciones ambientales bajo las cuales sus sucesores son criados y crecen hasta la madurez" (Ingold, 2018: 6). Estas condiciones consisten en la guía, el ejemplo, la crítica, la inspiración y el seguimiento para interactuar de forma vigilante en un ambiente formativo integrado por objetos, espacios, imágenes y otros seres, de modo que "los poderes personales de percepción y acción son desarrollados a través de la experiencia inmediata de participación sensorial con componentes humanos y no humanos del mundo habitado" (Ingold, 2003: 310).

Una consecuencia directa de lo expuesto por Ingold es que las aulas no deberían ser entendidas como lugares de reproducción de un conocimiento dado, sino como un medio a partir del cual se genera el saber. Es en la construcción de un nosotros en el salón de clase donde los participantes se articulan para dar paso a un conoci- 
miento emergente, de allí que el docente aprenda por medio del enseñar y de sus estudiantes. Por esta razón, todos los participantes son transformados a través de la experiencia educativa.

Bajo el mismo énfasis reflexivo, en la interacción con el mundo como fuente de significación, para la antropología contemporánea el conocimiento no puede entenderse solamente como una meta, es decir, un producto alcanzado. Para replantear esta postura, según Hastrup (2003), es necesario indagar cómo las preguntas, intereses, relaciones subjetivas y experiencias prácticas influyen en la forma como generamos y usamos el conocimiento, en consecuencia:

es el proceso de conocer el que conlleva el gran descubrimiento ontológico, no el resultado final. El deseo de simplemente saber y mostrar lo que el mundo ha intentado mantener oculto a la vista, debe complementarse con un deseo de mostrar cómo se produce el conocer, cómo se presupone y cómo afecta al objeto. La representación es engañosa, porque da la impresión de que el conocimiento es monológico y finito, mientras que en realidad es dialógico, temporal y profundamente procesual. (Hastrup, 2003: 241)

Partir de un énfasis en los procesos por medio de los cuales se produce el conocimiento implica que la investigación antropológica no se restringe a indagar en el mundo social por fuera de las universidades, sino que su visión académica también puede analizar las estrategias a partir de las cuales se genera el saber dentro del aula de clase. Es por esto por lo que Finkelstein (2019: s.p.) retoma las preguntas reflexivas de esta disciplina para guiar e impulsar su labor docente:

mi enfoque pedagógico hace eco de mi formación metodológica como antropóloga. Es decir, estoy a favor de las preguntas sobre las respuestas. Prefiero la curiosidad a la autoridad. Desarrollo tareas que privilegian el proceso sobre el resultado. En resumen, entiendo las artes liberales como una estructura a través de la cual a los estudiantes se les da el espacio para pensar, reflexionar y desafiar sus suposiciones sobre el mundo, preguntando: ¿Qué significa pensar críticamente? ¿Cómo hacemos preguntas y reaprendemos a ser curiosos? ¿Cómo comenzamos a desafiar nuestras opiniones y suposiciones con evidencia empírica? ¿Cómo nos sentamos con la incomodidad de desarmar y reconstruir un mundo que creemos conocer?

\section{Reflexividad en el ejercicio docente}

En las universidades, se enseña que la tarea de la antropología consiste en resaltar las múltiples posibilidades de existencia del ser humano para así problematizar universalismos que conducen a diferentes formas de violencia; por ejemplo, esencia- 
lismos en torno a la política, el género, la religión, etc. Por este motivo, para Grimson (2016:138), la meta de esta disciplina es "la búsqueda constante de comprensión, de descentramiento, de desplazamientos antietnocéntricos, de crítica implacable de los modos de estigmatización cultural, exclusión social y cerrazón política”.

Pero si esta es la razón ética y política de la antropología, ¿hasta qué punto sus medios de enseñanza han sido suficientes para despertar este llamado de sensibilidad, crítica y compromiso en sus estudiantes?, ¿las pretensiones de la antropología se encuentran alineadas con sus estrategias educativas? Considero que en Colombia hay una contradicción entre las metas de la antropología y las estrategias de su formación académica. Aunque los docentes tengan mucho que decir ante cómo los otros y ellos mismos conocen el mundo, no se ha utilizado este potencial reflexivo para transformar la enseñanza de esta disciplina en las universidades.

Si se busca que los estudiantes se comprometan con la tarea antropológica de problematizar el sentido común, primero es necesario que los docentes lo hagan ante el modelo educativo de su disciplina que han reproducido acríticamente. Si se pretende resaltar la importancia ética del diálogo de saberes, primero los docentes deben aprender a conversar con los estudiantes sin la autoridad magistral y sin negar las responsabilidades que implica su rol de educadores. Si el conocimiento que la antropología encuentra a lo largo del mundo se genera de forma dialógica, por consiguiente, sus dinámicas de enseñanza también lo requieren. Bajo esta última premisa, Ingold (2015: 48) afirma que

en el campo, los antropólogos aprenden; en clase, enseñan. Sin embargo, esto no significa que están recibiendo conocimiento en el primer caso y transmitiéndolo en el segundo. En ambos casos, sea con población local o estudiantes, los antropólogos colaboran en el proceso dialógico de su creación. Es a partir de traer los dos diálogos, en el campo y en el aula, y en un productivo interjuego, que el conocimiento antropológico es generado. Así, el diálogo en el aula es tan importante y tan integral para el proyecto antropológico como el diálogo en el campo. Tardíamente hemos empezado a reconocer la contribución de los colaboradores locales - antaño "informantes"- al avance de nuestro tema. Es hora de que reconozcamos las contribuciones de los estudiantes también.

La antropología no es solo teoría sobre el mundo por fuera de las aulas, porque su conocimiento también puede expresarse como una forma de pensar la educación dentro de los salones de clase. Debido a lo anterior, partir de una lectura dialógica del conocimiento en el contexto universitario conduce necesariamente a confrontar el énfasis excesivo en las clases magistrales y los seminarios. Estas dos modalidades de enseñanza, si bien son claramente útiles para desarrollar tareas específicas, pueden 
terminar desincentivando el compromiso en el aula por parte de los alumnos y los docentes si se convierten en la base de todo el proceso de formación.

Por un lado, las clases magistrales, en las que los profesores explican las ideas centrales de un texto acordado y cierran la sesión con preguntas, no incentivan la interacción en el aula, de hecho, sus sesiones pueden terminar por parecer conferencias para los estudiantes. En esta medida -y no he encontrado pocos casos-, los alumnos terminan por leer los textos después de clase, si es que los leen, porque el docente desglosa todos sus argumentos acostumbrándolos así a delegar el ejercicio analítico. Una consecuencia directa de esta modalidad de enseñanza es que el estudiante, finalmente, recuerda de manera parcial los debates del curso, no por su curiosidad y pensamiento crítico, sino por el grado de autoridad del profesor.

Por otro lado, para eliminar la jerarquía del aula, en las clases tipo seminario alemán los alumnos desarrollan los temas mediante exposiciones y realizan informes reflexivos de cada sesión. Esta estrategia de enseñanza delega la labor de enseñanza en los estudiantes, mientras los docentes ignoran que estos no cuentan con las herramientas necesarias para decodificar y usar la información de los textos. Por este motivo, es común, principalmente en los primeros semestres, que los alumnos terminen con diversas falencias teóricas, puesto que toman apuntes de las interpretaciones equivocadas de sus compañeros sobre el material del curso.

A grandes rasgos, la primera modalidad satura al estudiante de información porque desconfía de su rol activo en el aula, y la segunda da por sentado dicho rol, idealizando una voluntad autodidacta. En las clases magistrales, el docente pretende trasmitir información a la mente de sus estudiantes, pero no todos poseen las habilidades para estar atentos y seguir sus ritmos de enseñanza. De modo inverso, en las clases tipo seminario, el docente, al buscar que el estudiante dirija el ritmo de la clase, lo que hace es rehuir a su tarea de construir ambientes de aprendizaje en habilidades académicas básicas y de este modo ralentiza el aprendizaje colectivo.

La naturaleza dialógica del conocimiento impugna las dos modalidades de enseñanza señaladas porque la educación requiere del esfuerzo compartido en el aula, debido a que el saber necesita exteriorizarse ante los demás para que el sujeto pueda interiorizarlo. Es en la participación donde se despliega, dimensiona y evalúa el conocimiento, de allí su cualidad performativa y colaborativa. Por esta razón, la interacción en el aula no se puede dinamizar por medio de una concepción unilineal, desde el docente o el estudiante, pues ninguno tiene que guiar el ritmo de la clase, porque este debe surgir como una negociación, un tira y afloje entre ambos.

Que el ritmo de las clases sea negociado entre el docente y el alumno deja valiosas lecciones en torno a la reciprocidad del saber, lo cual permite trascender las relaciones verticales y horizontales en el aula. El estudiante aprende a ejercer un rol activo 
porque su opinión y sus contribuciones importan. De hecho, si no se compromete a retribuir el trabajo del docente con su participación, las clases no avanzan, ya que sus apuntes, preguntas, ideas, ejemplos y experiencias son la materia prima de cada sesión. De igual forma, el docente debe reconocer que los requerimientos de los cursos solo se pueden alcanzar si primero elabora un ambiente de aprendizaje basado en la formación de habilidades (como leer, tomar apuntes, argumentar y escribir) para poder articular, focalizar y ampliar el conocimiento que se elabora en el curso.

Ahora bien, para que en el aula exista reciprocidad del saber, el docente debe reconocer el rol esencial de la confianza y la curiosidad en sus procesos educativos. Primero, las capacidades intelectuales se edifican en habilidades emocionales. Por ejemplo, aprender a argumentar requiere que un estudiante tenga confianza en sí mismo para que pueda afrontar el miedo a equivocarse. Esta confianza se logra a partir del diálogo permanente en el aula, específicamente en el momento en que el estudiante comienza a abrirse ante los demás para compartir sus dudas académicas, sus deseos de aprender y sus conocimientos obtenidos en clase, lo cual le permite interiorizar un saber emergente y, simultáneamente, apoyar el proceso formativo de sus compañeros. Teniendo en cuenta lo anterior, para Shankar y Zurn (2O2O: s.p.), los estudiantes

deben comenzar a sentirse cómodos compartiendo sus ideas, asumiendo riesgos y disfrutando de la incertidumbre de saber que sus ideas están siempre inacabadas y pueden mejorarse aún más con la curiosidad crítica de sus compañeros y miembros de la comunidad. El compromiso entre pares y la comunidad permite que las ideas e innovaciones se agudicen con y junto a las personas para las que más importan.

Segundo, todo proceso educativo requiere de curiosidad. La enseñanza no se basa en compartir verdades, porque educar es aprender a interrogar el mundo en compañía de los demás. Es más, si la antropología consiste en la familiarización de lo extraño y la extrañeza de lo familiar, su experiencia en el aula no se debe basar en comunicar certezas, ya que de este modo se clausuraría de antemano el espíritu creativo y crítico de sus estudiantes. Aunque orientar clases les permite a los docentes aclarar y profundizar lo que entienden al explicarlo mediante nuevos ejemplos, también les ayuda a replantear lo que creen saber y a reconocer lo que no saben, lo cual puede impulsarlos a estudiar más.

Es contradictorio que, si bien el ejercicio docente acarrea ineludiblemente diversos cuestionamientos, los profesores no transformen las dudas de sus estudiantes en curiosidad, es decir, no la convierten en un deseo por explorar antropológicamente lo desconocido. Por ejemplo, cuando los docentes formulan preguntas esperando respuestas con datos puntuales intimidan a los estudiantes y terminan generando la 
idea de que el conocimiento solo se basa en memorizar certezas. Debido a lo anterior, según Shankar y Zurn (2020), los estudiantes dejan de ser curiosos porque no se les enseña a profundizar en ello. Así, terminan asociando la incertidumbre con emociones negativas, ya que no se les permite dudar y aprender de dicho proceso, de allí que no participen en clase.

Como respuesta a la problemática señalada, según Shankar y Zurn una formación comprometida con la curiosidad debe guiar la experiencia en el aula como un ejercicio investigativo. Esta estrategia permite que los estudiantes se acerquen creativamente a lo desconocido y, de esta forma, "los equipamos para que se comprometan con sus entornos sin el temor de perder el sentido de sí mismos cuando se enfrentan a diferencias, incógnitas o incertidumbres" (Shankar; Zurn, 2020: s.p.), y agregan:

Cuando los estudiantes desarrollan las habilidades para saciar su curiosidad, es probable que continúen por su cuenta, mucho más allá de los límites del aula. Como tal, las tareas deben llevar a los estudiantes a los preceptos básicos de la investigación: ¿Cómo hago las preguntas? ¿A dónde voy para responder a las preguntas? ¿Qué metodologías de investigación podría emplear para descubrir una respuesta? ¿Cómo puedo profundizar en mi campo de investigación? (Shankar; Zurn, 2O2O: s.p.)

Tal es la utilidad de concebir la educación como un ejercicio investigativo que su aplicación trasciende las universidades. Khoshman (2018) expone que, en su experiencia docente en Jordania, retomó los conocimientos de la antropología con la finalidad de pensar la exclusión social, el cambio generacional y sucesos de la vida cotidiana. Para ello, desarrolló sus clases como investigaciones colectivas:

Veo al maestro actuando como una especie de investigador etnográfico, liderando a los estudiantes de primaria y secundaria en la investigación de problemas sociales que afectan sus vidas utilizando métodos como la observación participante y las entrevistas. La participación de este tipo fortalecería el papel del maestro en la escuela y en la sociedad, y presentaría a los estudiantes y maestros el conocimiento local de primera mano. (Khoshman, 2018: s.p.)

\section{Apuestas experimentales de enseñanza}

\section{Redefinición de la lectura}

Los docentes de antropología se enfrentan diariamente a las falencias de lectura, argumentación y escritura de sus estudiantes, pero solamente enunciar esta crítica conduce, insospechadamente, a una posición demasiado cómoda que puede termi- 
nar por ocultar el papel de los profesores en la reproducción de dichas deficiencias. Por este motivo, Bourdieu y Passeron (2009:104) afirmaban críticamente que "decir con tono de lamentación resignada que los 'estudiantes ya no leen' o que 'el nivel baja de año a año' es en efecto evitar preguntarse por qué es así y sacar de allí alguna consecuencia pedagógica".

Las debilidades señaladas son, en parte, producto de la manera como se entiende el ejercicio de lectura. Todavía persiste en las universidades del país la concepción de que la lectura consiste en el registro del contenido de los textos, de allí que comprender se equipare a memorizar. Esto lleva a que se limite la sensibilidad del docente y del estudiante ante los libros por dos razones. Primero, el contenido de un escrito no preexiste enteramente a su lectura, puesto que este siempre emerge y se actualiza. En otras palabras, cada lector interpreta los textos desde sus referentes experienciales, lo cual puede clarificar, ampliar o distorsionar sus ideas. Por lo tanto, su comprensión no se puede limitar al escrito mismo, sino que requiere de información externa que dé sentido a sus ideas. Segundo, la información del texto no solo se reduce a su contenido, pues su forma es igual de relevante; es decir, el andamiaje argumentativo que ordena y potencia el contenido: ambas dimensiones se trenzan para guiar la experiencia lectora.

Frente al contenido, Eco (1993) expone que los autores dejan espacios a rellenar para que el lector tome la iniciativa interpretativa, es decir, que realice múltiples lecturas que actualicen los textos al completar sus vacíos. Esta condición no imposibilita su comprensión, sino que es la oportunidad para que la lectura sea un ejercicio de cooperación textual, por medio del cual el lector busca que "por muchas que sean las interpretaciones posibles, unas repercutan sobre las otras de tal modo que no se excluyan, sino que, en cambio, se refuercen recíprocamente" (Eco, 1993: 81). Antes de forzar lecturas subjetivas se requiere poner en diálogo complementario perspectivas diferentes para conocer las intenciones del autor, las competencias que requiere el lector y, a su vez, que este último se pregunte cómo sus expectativas afectan su interpretación.

Las reflexiones anteriores en torno a la interpretación de los textos poseen una implicación pedagógica. Los docentes no podemos buscar el sentido de los textos limitándonos a los textos mismos, es decir, la teoría no se puede explicar solamente desde la teoría. Paralelamente a las lecturas de clase es útil que los estudiantes cuenten con materiales de diálogo afines (series, películas, noticias, poemas, novelas, documentales, imágenes, crónicas, etc.) para poder actualizar y comprender las ideas de los textos. Este tipo de estrategia se denomina aula invertida, ya que se le da relevancia a la lectura de información complementaria anterior a la clase, lo cual crea un ambiente de aprendizaje estimulante. 
El parafraseo y el diálogo grupal también son estrategias por excelencia para la actualización de un texto. Se ha demostrado que cuando los estudiantes escriben en sus propias palabras los problemas evaluados, su posibilidad de resolverlos aumenta en gran medida (Pezzatti, 2018). Otros experimentos han evidenciado que, en la interpretación individual de datos estadísticos, se proyectan sesgos personales, pero cuando el análisis de los datos es grupal y deliberativo, la interpretación es mucho más acertada y objetiva (La Silla Vacía, 2019).

Frente a la forma, las clases no tienen que limitarse a indagar en las ideas de cada texto, así se desperdiciaría mucha información valiosa. De hecho, se requiere que los alumnos reflexionen sobre los problemas que formula el autor y el modo en que los resuelve mediante diversas herramientas argumentativas. Luego de identificar y evaluar las formas de los textos, los estudiantes pueden aprender a emularlas y transgredirlas en sus propios escritos. Por consiguiente, un estudiante aprende a escribir cuando usa las estructuras lógicas de los autores que lee. Una gran ventaja de la búsqueda anterior es que, al conocer el andamiaje del texto, el alumno puede sentir una mayor familiaridad con el autor, en vista de que aprende no solo a ver el mapa plano de sus ideas, sino también los relieves argumentativos que guiaron su comprensión.

$\mathrm{Al}$ ver el esqueleto argumentativo del texto, los alumnos identifican a su vez el trasfondo metodológico de su teoría, lo cual es esencial en la formación en antropología. Cuando no solo considera las declaraciones como hechos, sino como productos de estrategias investigativas, el estudiante comienza a reflexionar sobre los requerimientos técnicos y retóricos necesarios para producir los conocimientos que lee. En otras palabras, al estudiar la forma de un escrito no se pregunta simplemente qué conocen los autores sobre el mundo, sino también cómo estos conocen el mundo que describen. De este modo, surge la metacognición, teniendo en cuenta que los estudiantes, simultáneamente, aprenden a observar la realidad desde el punto de vista de los autores y a objetivarse a sí mismos como lectores para analizar cómo piensan y argumentan.

Como consecuencia de lo anterior, el plan de trabajo universitario de este nuevo siglo, antes de componerse simplemente de una lista de textos, puede pensarse desde el entretejido entre su contenido emergente y su forma argumentativa. Para ello es necesario integrar material de diálogo complementario que despierte curiosidad y, por lo tanto, atención. A su vez, los textos deben estar acompañados de preguntas orientadoras que sirvan para focalizar la sensibilidad del estudiante ante sus andamiajes argumentativos.

Al conversar en clase sobre el contenido y la forma de un texto, tanto el docente como el estudiante validan y fortalecen su interpretación, o pueden replantearla debido a que conocen perspectivas que no habían tomado en cuenta. De allí que, al 
participar en el aula, se calibre el juicio y se ofrezcan herramientas a los demás para que también lo hagan. A muchos estudiantes universitarios les cuesta participar en clase, pero si las sesiones no comienzan con la explicación de una teoría antropológica compleja, sino que inician con una conversación informal en torno al material de diálogo relacionado con el texto de la sesión (noticias, canciones, películas, novelas, etc.) y a la efectividad de su argumentación (¿en qué medida el autor logró convencer y mantener la atención de lector?), los alumnos comienzan a expresarse de forma más cómoda y fluida. De este modo, mientras amplían su capacidad de síntesis, se mejoran la confianza y los canales de comunicación en el aula, porque sus participantes se sintonizan en torno a un lenguaje común.

\section{Mediaciones tecnológicas en la enseñanza}

La pandemia del coronavirus generó un tránsito acelerado hacia la educación virtual. Actualmente, tanto docentes como estudiantes afrontan los nuevos desafíos, incertidumbres, deficiencias y potencialidades de esta modalidad de aprendizaje. Reflexionar sobre el miedo al cambio en la educación virtual es importante, porque este formato inevitablemente va a quedarse en las universidades después de la vacunación global, debido a las limitaciones financieras de estas instituciones para invertir en infraestructura y a las ventajas que ofrece la tecnología en relación con su amplio nivel de cobertura. Por lo tanto, en los próximos años las clases tenderán a ser esencialmente híbridas, mezclando cursos y módulos virtuales y presenciales.

Es importante mencionar que a algunos docentes que antes de la pandemia orientaban sus clases de forma magistral les cuesta en mayor medida adaptarse a los cambios tecnológicos, puesto que la educación virtual requiere de un aprendizaje activo y autodidacta por parte del estudiante, habilidades que los profesores no habían tenido en cuenta previamente. A su vez, tienen mayores dificultades porque las clases magistrales no pueden mantener durante mucho tiempo la atención del alumno en el medio virtual. Pero ante estos nuevos problemas comunicativos se asume de antemano que se deben enteramente a las deficiencias del formato virtual, evitando así reconocer la falta de capacitación del docente en competencias digitales.

Muchas de las críticas a la educación virtual consisten en nuevos miedos al cambio tecnológico, como cuando llegó el gramófono o el teléfono, lo cual produjo temores de que se acabarían los conciertos o los encuentros personales. Estas inseguridades ante el cambio virtual están impulsadas por la nostalgia generacional a partir de la cual se considera que solamente las formas previas de aprendizaje presencial son las únicas efectivas y legítimas, lo cual impide reconocer las amplias oportunidades que ofrece la tecnología contemporánea para fortalecer los procesos pedagógicos en las 
universidades; oportunidades con las que no contaban las generaciones anteriores y que desafían las formas tradicionales de enseñanza, al generar nuevos roles en docentes y estudiantes.

Es importante reconocer que las dinámicas y, en consecuencia, las metas de la enseñanza cambian con la tecnología. Por ejemplo, debido a que en las últimas décadas se ha multiplicado enormemente la producción de conocimiento antropológico, la memorización de los debates teóricos deja de ser una finalidad esencial en la enseñanza. Ello se debe a que, por un lado, por medio del internet los estudiantes pueden acceder fácilmente a una enorme cantidad de fuentes de información (textos, conferencias y comunicación personal con académicos) y, por el otro-paradójicamente por la misma razón-, pueden olvidar el material consultado dada la saturación acrítica de datos.

Por los tipos de desafíos, para Eco (2007), la labor del docente es invaluable en la era del internet, puesto que su tarea no consiste solo en informar sino también en formar. En otras palabras, enseñarle al alumno a filtrar la información y a pensar críticamente sus experiencias como parte de una realidad social más amplia. En virtud de ello, "lo que hace que una clase sea una buena clase no es que se transmitan datos y datos, sino que se establezca un diálogo constante, una confrontación de opiniones, una discusión sobre lo que se aprende en la escuela y lo que viene de afuera" (Eco, 2007: s.p.).

El docente no simplemente trasmite información, pues su labor es mucho más amplia: consiste en enseñar a sus estudiantes a construir hábitos para usar productivamente las herramientas que tienen a la mano para así profundizar en su formación académica. Es decir, un profesor no ofrece solamente conocimiento, sino que comparte la curiosidad, la utilidad y el deseo de interrogar al mundo y de desarrollar habilidades específicas para ello. En vista de lo anterior, el contenido del curso no es un fin, sino un medio para desarrollar habilidades de atención en torno a la lectura, la escritura, la argumentación, la expresión oral, el trabajo en equipo, la resolución de problemas, la inteligencia intersubjetiva y el pensamiento crítico, destrezas que requiere todo profesional.

Actualmente, los estudiantes tienden a consumir una alta cantidad de información heterogénea (redes sociales, noticias, memes, etc.); a razón de ello, cada vez es más común que se distraigan en las clases más tradicionales, debido a que estas les ofrecen muy pocos estímulos. Pero los docentes antes de sentirse intimidados por el hecho de que deben disputar la atención del estudiante con los nuevos dispositivos tecnológicos, deben reconocer con esperanza que esta es la generación con mayores herramientas pedagógicas disponibles. De allí, por ejemplo, la gran utilidad de las aulas invertidas para incentivar la participación en clase. 
Si los profesores saben que sus alumnos piensan visualmente, es necesario reforzar los canales de comunicación presencial y virtual relacionados con este estilo cognitivo. La utilidad de dirigir la atención de los estudiantes por medio de imágenes yace en que estas les ayudan a ampliar su curiosidad, descansar del diálogo extenso, sintetizar información y corroborar su comprensión. Salovaara (2019: s.p.) reflexiona sobre la importancia de las imágenes en sus clases de antropología, a partir de una vivencia cotidiana:

estaba en la exposición con mi hijo, que tenía unos doce años en ese momento, y él entendía cosas de las fotografías que no podría haber apreciado solo con la lectura. Vi el impacto de esas fotos en él, mientras pensaba en cómo estas comunicaban relaciones que de otra manera eran bastante difíciles de capturar.

Pero usar imágenes no es en sí mismo algo innovador en clase, de hecho, su saturación aburre fácilmente a los alumnos. Lo urgente es identificar que no toda imagen convence, dado que los estudiantes de esta nueva generación poseen mayores estímulos estéticos y, por lo tanto, cánones y necesidades más sofisticadas. En consecuencia, en los procesos educativos se debe invertir un mayor tiempo en configurar la fuerza visual y reflexiva del material pedagógico para poder asociar efectivamente emociones, ideas e imágenes. En suma, para que los docentes reconozcan la necesidad de capacitarse en el manejo de las nuevas herramientas tecnológicas, es necesario que primero sean conscientes de que sin empatía estética no hay atención en el aula.

\section{Transposición didáctica}

Para mejorar la efectividad de los procesos educativos, los docentes necesitan escribir, leer y conversar sobre las experiencias pedagógicas en el aula, de este modo, aprenden a evaluar crítica y propositivamente la forma como enseñan. Este es el compromiso ético que se busca alcanzar recientemente por medio del Scholarship of Teaching and Learning (SoTL), una apuesta por compartir estrategias educativas para generar una retroalimentación entre docentes y estudiantes. En consonancia directa con este compromiso, existen plataformas de difusión de herramientas pedagógicas como Society for Cultural Anthropology ${ }^{1}$ y Teaching and Learning Anthropology ${ }^{2}$, las cuales permiten socializar ejercicios experimentales en el aula.

1. https://culanth.org/

2. http://teachinglearninganthro.com/ 
A continuación, caracterizaré cuatro estrategias innovadoras en la enseñanza de la antropología guiadas por la transposición didáctica, es decir, por la adaptación del contenido académico a un nivel lúdico e interactivo para facilitar su enseñanza. Valga resaltar que estas nuevas propuestas educativas no son solo prácticas que se suman a los repertorios pedagógicos anteriores, sino ejercicios que impugnan directamente las estrategias bajo las cuales se han entendido el saber y el aprendizaje en la antropología. Por esta razón, el mundo académico está llamado a "repensar la estructura de la universidad a la luz de las nuevas modalidades de conocimiento y las nuevas ideas sobre los procesos mediante los cuales el conocimiento se adquiere y se renueva" (Hastrup, 2003: 245). Es decir, redefinir qué es y cómo surge el saber implica, necesariamente, la transformación de la planificación pedagógica en las universidades.

Reflexionando sobre la vida cotidiana y académica de sus estudiantes, Seaver (2018) orientó un seminario enfocado en ampliar la comprensión de qué es la atención por medio de lecturas, ejercicios y artefactos. Antes de tomar la atención como una categoría clara, dada y universal, sus alumnos exploraron qué se considera atención, y cómo se organiza y valora culturalmente, puesto que "aprendemos cómo prestar atención y a qué prestar atención de otras personas, y asistimos dentro de entornos tecnológicos mediados y diseñados para dar forma a nuestras prácticas de atención. Nadie presta atención solo" (Seaver, 2018: s.p.).

Dicho seminario se enfocó en tres temas de estudio: "metodología etnográfica (¿cómo prestan atención los antropólogos?), el sensorium (¿cómo atendemos a través de nuestros diversos sentidos?) y términos clave atencionales (¿qué es la distracción? ¿sobrecarga? ¿la economía de la atención?)" (Seaver, 2018: s.p.). De esta manera, cada semana, los estudiantes relacionaron los textos del curso con noticias, sonidos escuchados en caminatas, experiencias en la web, artefactos tecnológicos, documentales, talleres de aromas y degustación, obras expuestas en la galería de arte de la institución, entre otros.

En complemento a los textos, se realizaron ejercicios prácticos que consistían en registrar, mediante escritos, dibujos o diagramas, qué los distraía, anotar qué percibían de un espacio concurrido y detallar cómo alguien que trabaja está atento ante su labor. A su vez, se propuso que los alumnos analizaran sus experiencias de percepción en un área urbana y en el uso de internet frente a qué los atraía, qué es difícil de atender y qué pasaba cuando intentaban focalizar su atención.

Problematizando la separación entre la abstracción teórica y la sensibilidad práctica del estudiante, Mauksch (2018), en su seminario "Cuerpo, parentesco y género" reflexionó sobre la importancia del cuerpo en la generación del conocimiento. Con base en dicho propósito, buscó 
eliminar parte de la pesadez y la autoridad silenciadora de los textos académicos con los que los estudiantes universitarios a menudo luchan, haciendo que esos textos sean más accesibles y expandiendo el espacio (emocional, artístico, comunicativo) de respuestas posibles. En lugar de preguntar “¿Cómo piensa este autor? ¿Cómo discute ella?”, este experimento instó a los estudiantes a considerar: “¿Qué provoca leer este texto en mí? ¿Qué me imagino y siento?”. (Mauksch, 2018: s.p.)

Para llevar a cabo esta dinámica, los estudiantes debían visualizar imágenes mentales de las ideas de los textos, esto les sirvió como una herramienta de entendimiento recursivo y colectivo para criticar y ampliar las interpretaciones propuestas. Además, tradujeron ideas de Tim Ingold, Judith Butler y Susan Bordo, por medio de materiales de papelería, para fortalecer su comprensión. Los alumnos también realizaron mapas sociales sintetizando ideas de Lisa Law, graficando los complejos vínculos que describía entre el territorio y el parentesco. Asimismo, elaboraron un performance sobre un ensayo de Evelyn Blackwood acerca del tránsito de género por medio de una línea de cruce en el suelo del salón.

Usando estratégicamente herramientas tecnológicas en el aula, Parikh (2018: s.p.) propuso a sus alumnos que escucharan podcasts como material complementario a sus clases, para que ellos luego elaboraran uno con la intensión de reflexionar acerca de "la importancia de pensar en nuestras audiencias -estudiantes de pregrado, colegas antropólogos, el público-". Vale resaltar que este formato está tomando un mayor protagonismo en la comunicación del conocimiento académico al permitir una amplia difusión, actualización e integración del saber antropológico 3 .

Profundizando en la relación entre antropología y política, Mariner (2018) incentivó a sus alumnos a que llevaran el conocimiento académico por fuera del aula. Bajo esta meta, realizaron una campaña antirracismo en su universidad, analizando críticamente discursos sobre el uso de armas. En este ejercicio, Mariner resaltó una de las reflexiones de sus estudiantes:

El objetivo de este proyecto era utilizar la educación como una herramienta de empoderamiento (...). Esta clase transformó los tópicos sobre raza, diversidad e inclusión en directivas materiales e intencionales sobre las que se podría actuar. Así es como quería que nuestro proyecto fuera visto y entendido. El objetivo nunca fue la neutralidad. Siempre fue decirle la verdad al poder. (Mariner, 2018: s.p.)

3. Por ejemplo, la página web de podcast AnthroPod (https://soundcloud.com/cultural-anthropology). 
Este tipo de metodologías educativas innovadoras cobra mayor relevancia en el panorama profesional de la antropología. Por ejemplo, el proyecto Transca (Translating Socio-Cultural Anthropology into Education) es una apuesta internacional que busca sistematizar, ampliar e innovar en las estrategias antropológicas de enseñanza para que "los docentes puedan aplicar métodos y herramientas antropológicas con respecto a cuestiones sociales centrales y conceptos de las ciencias sociales (como interculturalidad, diversidad, migración, integración, género, interseccionalidad, etc.)" (Sarikoudi, 2019: s.p.).

Conocer las nuevas apuestas pedagógicas de la antropología me ha inspirado a ser más experimental como docente al invitarme a dudar de lo que creo saber hacer. La reinvención educativa es sumamente necesaria a causa de que cada estudiante posee debilidades, necesidades, fortalezas y presaberes diferentes que solo se pueden identificar y abordar al diversificar las estrategias pedagógicas. Pero traducir un contenido teórico en múltiples estrategias didácticas no implica salir de los debates antropológicos, sino profundizar en estos para imaginar nuevos lineamientos operativos en su enseñanza. A continuación, describiré tres experiencias personales guiadas desde la transposición didáctica.

A partir del estudio de la diversidad humana, la antropología ha identificado que el conocimiento no existe simplemente en un plano inmaterial del pensamiento. Por el contrario, los objetos son a su vez sostén y apoyo de los procesos cognitivos, por lo que son partícipes activos del mundo social ${ }^{4}$. El reto que tenemos como docentes es extraer las implicaciones pedagógicas de las reflexiones teóricas que abordamos. Por ello, en la asignatura Historia de la Teoría Antropológica expuse debates clásicos y modernos por medio de objetos que llevaba a la clase, como tótems, plantas, esqueletos metálicos, lupas, etc. Este ejercicio tenía la finalidad de que en los exámenes orales los estudiantes realizaran presentaciones de diferentes teóricos con base en objetos, para que pensaran a través de estos.

En el curso Fundamentos en Etno y Sociolingüística, como ejercicio final, los estudiantes realizaron etnografías de la comunicación por medio de las cuales analizaron actos cotidianos de habla. Entre estas investigaciones, se han destacado trabajos sobre el barrismo, las iglesias cristianas y los habitantes en condición de calle. Recientemente, los alumnos han acompañado dicha actividad con la síntesis de sus investigaciones a través de un podcast, lo cual ha incentivado en ellos nuevas formas de reflexividad sobre la manera en que elaboran y representan el conocimiento. 
En la asignatura Estructuralismo en la Antropología, el trabajo final consistió en elaborar un fanzine sobre los debates teóricos de la materia. Esta última idea la retomé del blog del antropólogo Nicholas Kawas , en el cual se propone representar, mediante este formato, cartas imaginarias entre teóricos, un libro de recetas de conceptos, el Instagram de un académico, un manual de cómo ver el mundo de acuerdo a las corrientes teóricas, etc. En uno de los trabajos más destacados del curso, se creó el Instagram de Claude Lévi-Strauss, tarea estética que logró condensar de forma panorámica el amplio contexto histórico y teórico de este antropólogo (Figura 1).

FIGURA 1 Cuenta de Instagram de Claude Lévi-Strauss
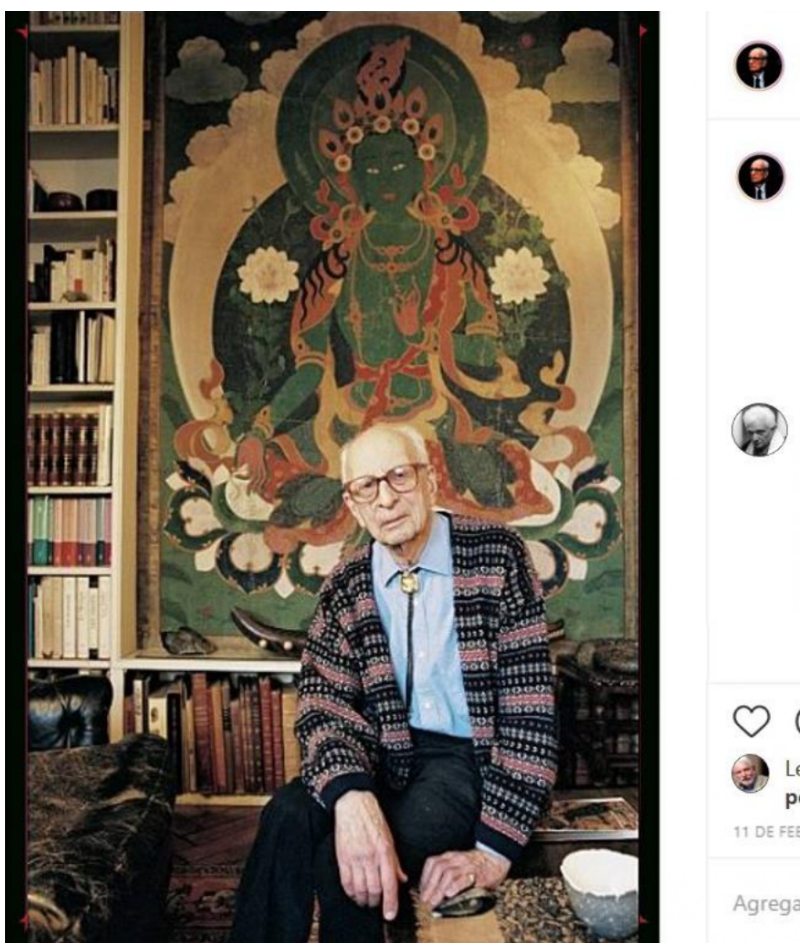

c.levi-strauss $\bullet \cdot$ Siguiendo

c.levi-strauss *

Organizamos nuestra experiencia a partir de sistemas lógicos finitos a los que el etnógrafo debe trabajar por acceder $\circledast$ 2 sem

jacquesderrida $\otimes$ Estructura estructurada estructurado la estructuralidad de la estructura $:$ No existen los sistemas finitos ni un centro que estabilice esos sistemas cambiantes e inestables. 2 sem 4 Me gusta Responder

(7) Les gusta a descola, jacqueslacan y 55,345 personas más

11 DE FEBRERO 
Al utilizar herramientas recursivas para la apropiación del conocimiento, surgen dudas sobre si esto sacrifica la complejidad de las teorías al punto de trivializarlas. Para resolver dicho interrogante, es necesario preguntar cuáles son los logros que los docentes quieren alcanzar en clase: ¿los profesores buscan que el estudiante memorice y repita detenidamente ideas, las cuales puede olvidar fácilmente y conocer resumidamente por internet, o que tenga una imagen panorámica de las teorías, acompañada de curiosidad, atención y disfrute estético generado por el ejercicio práctico? Si se supone que la complejidad es la característica inherente de todo conocimiento legítimo, no se reconoce que el saber requiere de su síntesis para poder ser interiorizado. Los docentes deben abandonar el temor a lo simple, de allí el llamado pedagógico de Finkelstein (2019: s.p.):

\begin{abstract}
Después de más de una década de trabajo de campo en la India, me acostumbré no solo a saber cosas (o al menos a saber más que mis alumnos), sino también a buscar complicaciones, a sacar contradicciones. Mi objetivo era animar a mis alumnos a tomar lo que creían saber sobre el mundo y hacerlo más complejo. Ahora me encuentro haciendo lo contrario. Les pido que piensen en lo que creen saber y luego lo hagan simple. ¿Qué es lo que realmente sabes con seguridad, y cómo lo sabes?
\end{abstract}

Los ejemplos anteriores muestran que, cuando los estudiantes enseñan lo que saben mediante herramientas didácticas, profundizan en su aprendizaje. Ahora bien, el lector puede preguntarse bajo qué principios y de qué manera se puede comenzar a experimentar en el aula. Como punto de partida, Shankar y Zurn (2020) invitan a trabajar en lo que denominan una pedagogía críticamente curiosa, la cual consiste en desafiar lo que se cree saber sobre la enseñanza, el qué, el cómo y el dónde se enseña, para así incentivar formas de curiosidad que problematicen y se reimaginen el mundo al crear nuevas formas de pensamiento en estudiantes y profesores. Para ello, plantean cuatro prácticas afectivas: 1) reconocer al otro como ser relacional y transformador; 2) crear formas de comunicación que partan de la empatía; 3) incentivar escenarios en los que se aprenda a habitar la incertidumbre; y 4) generar una imaginación política que critique las múltiples formas de violencia en la vida cotidiana. Además, sugieren prácticas específicas para cultivar la curiosidad en el aula por medio de seis propuestas educativas:

(1) hacer que los estudiantes participen en el proceso de decidir los objetivos y el contenido de los trabajos, (2) hacer que la curiosidad sea una parte explícita de la iniciativa de los trabajos, (3) cultivar una mentalidad de investigación en los estudiantes a través del protocolo de los trabajos, (4) proporcionar variaciones multimodales a la estructura de los trabajos, (5) vincular los trabajos a las experiencias de los estudiantes fuera de la 
clase, y (6) crear un entorno de colaboración en el que se puedan discutir los resultados de los trabajos. (Shankar; Zurn, 2O2O: s.p.)

\section{Desafíos de la enseñanza en antropología}

\section{Inequidad intelectual y aplicabilidad del saber}

En la enseñanza de la antropología, las relaciones globales e históricas de poder se manifiestan en las hegemonías intelectuales que los estudiantes leen en sus genealogías y diversidad de autores. Por tanto, si los planes de estudio no son diseñados de una manera crítica reducen la imaginación de lo que ha sido, es y puede ser la antropología. Por ejemplo, en el caso de la antropología ambiental, Guarasci, Moore y Vaughn (2018: s.p.) se preguntan por qué la citación académica importa:

¿Es nuestro canon adecuado para abordar las posibilidades y vulnerabilidades de los rápidos cambios ambientales contemporáneos?, ¿cómo los vocabularios de nuestro campo amplían o excluyen nuestras trayectorias de investigación?, jestamos, como campo, subestimando sistemáticamente las contribuciones de mujeres, personas de color, autores indígenas y otros cuyo trabajo podría hablar o zanjar las diferencias?

Dadas las preocupaciones mencionadas sobre la inequidad intelectual, la antropología contemporánea hace un llamado crítico para visibilizar las voces excluidas de la disciplina. Por esta razón, se resalta la necesidad de realizar genealogías disidentes ante su historia hegemónica y elaborar diálogos plurales en torno a las múltiples antropologías del mundo (Buell et al., 2019; Durrani, 2019; Lins; Escobar, 2008). A razón de lo anterior, en los últimos años esta disciplina ha comenzado a valorar y reivindicar la diversidad, no solo de los grupos humanos, sino también de los autores que se trabajan en el aula.

Cabe agregar que la falta de renovación en los temas de enseñanza en antropología puede no solo reproducir la inequidad intelectual, sino también la laboral. Por ejemplo, para Kawa (2018), esta disciplina amplía la inequidad social en su pirámide académica, en vista de que las universidades más prestigiosas en Estados Unidos producen la mayoría de los docentes en los doctorados de antropología del país. Esta distribución inequitativa de los puestos académicos no se debe necesariamente a la calidad de sus programas, sino al prestigio que heredan sus egresados de las universidades y los docentes. Para asegurar la inserción laboral de profesionales que no provengan de instituciones élite, las demás universidades han tenido que transformar sus planes de enseñanza. 
Una respuesta común es enfocarse más explícitamente en los campos aplicados, preparando a los estudiantes para carreras en el gobierno, las ONG y el sector privado. Un mayor énfasis en la capacitación interdisciplinaria-emparejar los títulos de antropología con la capacitación en ingeniería, ecología, estudios de medios o salud pública- es otra ruta, y una que muchos programas están considerando. (Kawa, 2018: s.p.)

Aun así, Kawa (2018) considera que los programas de antropología que no participan de las jerarquías académicas y se enfocan directamente en temas aplicados son los más exitosos. Esta reflexión se puede extrapolar al contexto colombiano. Los programas académicos del país no deben ocultar a sus futuros egresados las posibilidades reales de aplicación de su formación teórica. En Colombia, dada la baja financiación estatal en educación, hay una escasa oportunidad de ser docente universitario y, aún más, de realizar investigaciones académicas. Por lo tanto, si bien es necesario que sus programas posean una base educativa fuerte en investigación antropológica, la enseñanza universitaria debe desarrollar habilidades que estén más acordes con la proyección laboral de sus futuros profesionales.

Los programas de antropología pueden adaptar sus planes de estudio para abrirse a más campos del saber, por ejemplo, salud pública, educación, marketing e innovación tecnológica, conservación y medioambiente, género y derechos humanos, medios alternativos de comunicación, desarrollo rural, fortalecimiento comunitario y políticas públicas; además de enfocarse, en una mayor medida, en la gestión de proyectos y la formación en investigación cuantitativa sobre cambios demográficos y redes sociales. Por todo lo anterior, es fundamental que las clases partan de un aprendizaje basado en la resolución de problemas, para que los estudiantes conozcan y se preparen ante las dinámicas futuras de su vida laboral.

Enfocar la formación universitaria del país en una antropología aplicada no implica sacrificar sus aportes teóricos, más bien conduce a actualizarlos desde los debates políticos y las proyecciones laborales del presente. Pero no es que las antropologías contemporáneas sean superiores a las del pasado y nos den respuestas más acertadas, sino que nos ofrecen preguntas contemporáneas sobre problemas contemporáneos. Es preocupante que los estudiantes terminen aprendiendo conocimientos que nunca van a aplicar dada la desactualización teórica de sus programas académicos. Esta es una gran debilidad en varias universidades del país, puesto que parte de los conceptos que son legados de la antropología se revelan cada vez más imprecisos para entender y actuar profesionalmente en el nuevo mundo que surge ante nuestros ojos tras la pandemia. 


\section{El problema del holismo}

La antropología colombiana es heredera del modelo boasiano que postula su división subdisciplinar en antropología social, antropología biológica, lingüística y arqueología. Esta categorización norteamericana se edificó en la consideración de que la vida social es una totalidad que se puede conocer desde una lectura integral de la realidad. El problema de dicha visión holista es que los estudiantes no encuentran evidencias de su articulación ni dentro ni fuera de las aulas de clase. Es más, dicha división lleva a pensar que los programas boasianos parecieran tener diferentes carreras en una sola.

No es exagerado sostener que este modelo no funciona y nunca lo ha hecho. Para Bubandt y Otto (2010: 4), si bien el holismo es central en la historia de la disciplina, sobre este se ha hablado y enseñado más que escrito:

a pesar de las muchas referencias al holismo, las reflexiones explícitas sobre el holismo no han sido la regla en la antropología. Si el holismo era un eje central en antropología, tenía más el carácter de ser un tótem que una dimensión teórica elaborada.

La pretensión holista, antes que integrar investigaciones y departamentos, ha terminado por crear trincheras epistemológicas entre docentes. Por esta razón, la antropología colombiana pareciera carecer de leguajes comunes que aglutinen la amplia heterogeneidad de sus profesionales. Pero esta falta de comunicación no debe llevar necesariamente a dividir los programas académicos, como propone Restrepo (2018) para el caso de la antropología social y la arqueología, dada la supuesta falta de aportes académicos mutuos. Por el contrario, como exponen Graeber y Wengrow (2020), el diálogo entre la antropología y arqueología sobre la historia humana es sumamente necesario porque permite ampliar nuestra imaginación y crítica ante los modelos políticos del presente. Es más, Goldstein (2016:254) pone en evidencia que existen múltiples articulaciones productivas entre ambos campos de conocimiento y por este motivo poseen un futuro compartido:

parece que estamos avanzando en muchas direcciones nuevas al mismo tiempo, pero nos reunimos ocasionalmente en nuevos tipos de conversaciones. Esto parece ser un signo de un campo maduro, y quizás la mejor manera de convivir es abandonar la idea de una subdisciplina que intenta caracterizar toda la trayectoria intelectual de otra subdisciplina.

El punto para resaltar es que no debemos ser nostálgicos ante la falta de unificación académica en la antropología porque esta es una condición inherente a toda disciplina. En el caso de la antropología, su identidad, como sostiene Clifford (2005), 
es heterogénea, dinámica y se negocia permanentemente mediante la interdisciplinariedad. Por ello, los objetos, métodos, paradigmas y finalidades de las antropologías del pasado son rearticuladas, desafiadas y reinventadas por las múltiples antropologías del presente que conversan con otros campos del saber.

Un ejemplo de la importancia de las negociaciones y aprendizajes entre disciplinas lo proporciona Hastrup (2018), a partir de su investigación sobre las variaciones y la adaptación climática en el ártico, en compañía de biólogos y arqueólogos. Esta antropóloga resalta que las conversaciones grupales posibilitaron que todos los investigadores ampliaran su concepción y lectura del paisaje. De este modo, cada participante permitió que surgieran espacios de duda ante su saber, fueran mucho más conscientes de la forma diferencial e incompleta en que percibían el mundo desde sus hábitos académicos y formularan reflexiones alternativas en su investigación. Por este motivo, Hastrup (2018: 332) hace un llamado a la sensibilidad y el diálogo investigativo: "para que la colaboración sea más que un ejercicio aditivo, simplemente extendiendo el campo antropológico lateralmente, por así decirlo, hay que permitir que se vea afectado por paisajes vivos, vistos y sentidos desde muchas perspectivas a la vez".

Si bien la antropología social, la biológica y la arqueología ${ }^{6}$ poseen una particularidad innegable de métodos, lenguajes, trayectorias históricas y capacidades institucionales, ello no hace que sean intrínsecamente iguales o diferentes. Más bien, sus vínculos son emergentes, pues dependen de los problemas que las separen o equivalgan dentro y por fuera del aula de clase. En el contexto nacional, la causa de que estos campos del saber no se articulen es consecuencia de que no hacemos preguntas suficientemente amplias que crucen sus diferentes aportes.

Las trasformaciones geopolíticas contemporáneas, el acople radical de la tecnología en las vidas cotidianas y los impactos del cambio climático son eventos globales que imposibilitan separar el mundo social, ecológico y material. Tal es la complejidad de dichos cambios, que la antropología social en sí misma no es suficiente para encarar, estudiar e intervenir en estos temas, los cuales cada vez serán más trascendentales para la proyección laboral de sus profesionales.

6. La antropología lingüística se ha considerado como un campo subdisciplinar porque no se ha evaluado que esta división clásica del modelo boasiano partía erróneamente del determinismo lingüístico, pero esta no es un campo específico de conocimiento, sino un énfasis del análisis social que permite abordar dimensiones específicas de la experiencia de campo. De hecho, en Colombia, se ha hablado nostálgicamente de la falta de antropología lingüística en las universidades, pero hay muy pocas maestrías en el mundo especializadas en este tema, y el determinismo lingüístico ha sido teóricamente abandonado porque el lenguaje humano ya no es el referente total de la explicación teórica, como se postulaba desde el estructuralismo. 
Valga preguntarse entonces: ¿es posible explicar los nuevos umbrales y límites de la democracia sin tener en cuenta los desarrollos tecnológicos?, ¿historizar la profunda relación del ser humano con los objetos no es la base para entender los impactos actuales de la automatización?, ¿el conflicto armado en Colombia se puede analizar sin considerar el medioambiente?, ¿la urgencia de la gestión ambiental en el marco del cambio climático no compete por igual a la antropología social, la biológica y la arqueología?

El llamado anterior no es simplemente a fusionar subdisciplinas, sino a desafiar su comprensión como dominios intelectuales plenamente unificados y delimitados. Se necesita de problemas amplios que no predelimiten la perspectiva de su abordaje, sino que requieran retomar las diferentes herramientas de la antropología y de otros campos del saber. Que la antropología pueda existir más allá de la división boasiana evidencia que esta se reinventa constantemente mediante un proceso que consiste "menos sobre crear consensos que manejar el disenso, menos sobre mantener una tradición central que acerca de negociar fronteras y construir coaliciones" (Clifford, 2005: 24).

A causa de la renegociación permanente de su identidad, cuando la antropología contemporánea comienza a ser partícipe de las discusiones en torno al Antropoceno, muchas veces de forma crítica, pero propositiva, surgen articulaciones colaborativas sumamente amplias y productivas con otros campos del saber. Bajo este nuevo debate, se empiezan a congregar artistas plásticos, científicos cognitivos, filósofos, médicos, ecólogos, geógrafos, geólogos, químicos, diseñadores visuales, arquitectos, historiadores ambientales y cineastas, entre otros. Estos diálogos emergentes que problematizan la relación del ser humano con la naturaleza están comenzando a abrir nuevos horizontes intelectuales y políticos para las antropologías por venir.

\section{Articulación con el arte}

Las ciencias sociales tienden a poseer dos falencias comunes que han limitado su impacto en el mundo: el lenguaje críptico y la falta de articulación con el arte. Intentando corregir estas debilidades, en los últimos años las universidades han tenido un mayor interés por la divulgación científica. Actualmente, se están elaborando plataformas y metodologías experimentales que permiten comunicar el saber académico ante un público no especializado, ya que la divulgación está dejando de ser un deber institucional para constituirse como un compromiso ético de los investigadores.

Este compromiso crece cada día, puesto que los académicos del siglo XXI, en contraste con las generaciones anteriores, cuentan con mayores herramientas tecnológicas y requerimientos comunicativos para difundir el conocimiento de sus in- 
vestigaciones. Hoy los docentes e investigadores son cada vez es más conscientes de que una tesis o un artículo no son suficientes para contribuir a la sociedad; se requiere de estrategias recursivas de divulgación científica, que no comuniquen simplemente un saber preexistente, sino que elaboren nuevas formas de apreciar el conocimiento.

Para liberar el saber de los muros institucionales, el arte es un aliado central que le permite a la antropología tener una voz activa en las problemáticas globales. La relevancia de este vínculo yace en que, por ejemplo, las crisis ambientales son a su vez crisis estéticas. La falta de acciones reales ante los problemas climáticos se debe, en parte, a que carecemos de medios estéticos para reconocer, conversar y transformar nuestra relación con el medioambiente. Es importante reconocer esta carencia de diálogo porque, como afirma Charles F. Kennel (Diemberger et al., 2012: 227) sobre el cambio climático,
al final, todo se reducirá a la comunicación pública. Las decisiones no se tomarán ni se aplicarán sin la comprensión del público. Yla pregunta más importante para todos y cada uno de los individuos en el público es ¿qué significará el cambio climático para la gente y las cosas que me importan? Aquí es donde las disciplinas humanas deberían brillar.

Teóricamente, es posible encontrar diversas reflexiones sobre el vínculo existente entre la antropología y el arte. Frente al valor académico del arte, Willeslev y Suhr (2013: 1) afirman que el montaje es un recurso heurístico que permite abarcar escenarios como el cine, los documentales, las exhibiciones etnográficas, la escritura etnográfica, etc., y que "retiene el poder de sugerir nuevas formas de percibir relaciones entre las expresiones artísticas, la imaginación académica y la vida social". Para Willeslev y Suhr (2013), las cosas del mundo no se presentan a sí mismas de forma trasparente, por lo cual es necesaria la combinación de elementos heterogéneos por medio del montaje para que surja un exceso de sentido que permita que lo invisible surja, rompa el sentido común y ensanche nuestra comprensión de lo existente. La idea de que el montaje evoca lo invisible resuena con otros debates contemporáneos de la antropología.

De forma similar, para Ingold (2018: 68), el arte tiene un potencial antropológico en la medida que "sirve para llevar las cosas a la plenitud de su presencia, ponerlas 'sobre la mesa', liberarlas de las determinaciones de fines y objetivos. El arte que es antropológico permite que las cosas sean ellas mismas". Por su parte, para McLean (2017), esta disciplina no se puede reducir a los mundos humanos, porque existimos por medio de relaciones más que humanas. Este reconocimiento obliga a dialogar con el arte y la literatura a causa de que sus fuerzas expresivas permiten pensar nuestra realidad más allá del antropocentrismo. McLean (2017: X) considera que, 
por medio de dicha conversación, la antropología "podría entenderse a sí misma menos como el estudio de una humanidad objetivada que como la exploración abierta y performativa de posibilidades alternativas de la existencia colectiva, de nuevas formas de ser humano y de otras que humanas".

Conocer el mundo y representarlo no son dos procesos académicos opuestos. La investigación científica contemporánea demanda para ambos la misma sensibilidad, imaginación y recursividad. Por ello, el arte es un aliado directo de la pedagogía, pues a partir de este despertamos la atención ante el mundo que nos rodea. Si la antropología busca fusionar la reflexión intelectual y el disfrute estético, no debe limitar la expresión de su conocimiento a textos, pues requiere del montaje de sonidos, imágenes, narraciones, objetos, etc., para desafiar y ampliar la visión de la realidad dentro y fuera de las aulas de clase.

Actualmente, existen diversas plataformas virtuales comprometidas con la tarea de difundir y crear nuevas experiencias de conocimiento académico que deben ser resaltadas. Universidades, centros de investigación y grupos académicos están produciendo más libros y páginas interactivas con el fin llegar a una población más amplia al momento de socializar resultados de investigación. En el caso de la antropología, por ejemplo, Illustrating Anthropology presenta nuevas formas de conocimiento antropológico a través de múltiples medios ilustrados. Por su parte, Feral Atlas ${ }^{8}$ muestra los entrelazamientos de los seres humanos y no-humanos en medio de la expansión global de infraestructuras.

También se puede resaltar Anthropology for kids9, un proyecto que ensancha la curiosidad de los niños al presentar de una manera accesible el saber antropológico. De forma similar, en el caso colombiano, se encuentra el trabajo innovador del Laboratorio de Antropología Abierta ${ }^{10}$, el cual ha elaborado material pedagógico para niños en el libro ilustrado Antropología Xñ: Migración (Álvarez et al., 2020). A su vez, para difundir el conocimiento antropológico por fuera de la academia, este laboratorio ha traducido artículos académicos en cómics. Para finalizar, en sintonía con lo anterior, la novela gráfica Caminos condenados (Ojeda; Guerra; Aguirre; Díaz, 2016) y el cómic documental Recetario de sabores lejanos (Ojeda; Serna; Arias, 202O) son dos libros que describen conflictos socioambientales en Colombia de una manera

7. https://illustratinganthropology.com/

8. http://feralatlas.org/

9. https://a4kids.org/

10. https://www.antropologiaabierta.org/ 
tan creativa y emotiva que invitan a la academia a ser cada vez más experimental en su apuesta por comunicar su conocimiento.

En suma, la universidad del siglo XXI está llamada a crear nuevos canales de expresión del conocimiento científico por medio del trabajo artístico. Los docentes, para ser efectivos en el aula, y los investigadores, para tener un mayor impacto en la sociedad, deben reconocer el rol esencial del arte para trenzar el saber intelectual con la experiencia estética. No podemos olvidar que el arte es el motor de la curiosidad, y la curiosidad, el del pensamiento crítico.

\section{Conclusiones}

Las frustraciones de mi pasado como estudiante y las esperanzas de cambio como docente son las rutas de autocrítica e imaginación que he recorrido para elaborar el presente escrito. He transitado esta ruta impulsado por una pregunta cargada de incertidumbre y curiosidad: si la antropología no retoma los criterios de validez científica de las demás disciplinas, sino que construye sus marcos de objetividad por medio de su reflexividad, ¿por qué no establece sus propios criterios de enseñanza universitaria, con base en el saber que tiene sobre el ser humano?

Como respuesta a dicho interrogante, este artículo sostiene que la calidad de la formación universitaria en antropología se puede ampliar si su conocimiento se traduce en estrategias pedagógicas en el aula. Las respuestas que buscan los docentes ante los desafíos educativos no se encuentran por fuera de su saber, sino dentro de este. La antropología no interroga solamente la realidad externa a los salones de clase, sino que también puede problematizar sus estrategias de enseñanza dentro de estos y ofrecer diversas herramientas para fortalecer su aprendizaje.

Para sustentar este argumento, en un primer momento, se expuso que la antropología contemporánea entiende la educación como la creación de ambientes de aprendizaje. Luego, se resaltó la necesidad de confrontar las falencias del ejercicio docente al replantear la concepción de la lectura, integrar herramientas tecnológicas en la enseñanza y visibilizar ejercicios educativos experimentales. Por último, se expusieron los desafíos de la docencia en antropología relacionados con la inequidad, el holismo y el arte.

Como conclusión, este artículo es una invitación para que, en los programas de antropología de Colombia, no se considere el conocimiento académico solamente como una teoría sobre el mundo, sino también como una práctica dentro del aula que demanda la transformación urgente de las estrategias y los roles tradicionales de enseñanza. Los desafíos laborales, intelectuales y políticos de este nuevo siglo 
requieren que estudiantes, docentes y directivos se sienten a conversar sobre la manera como la formación profesional debe rediseñarse. No obstante, este cambio solo se impulsará cuando la comunidad universitaria identifique y afronte las implicaciones educativas del conocimiento antropológico.

\section{Referencias}

Álvarez, Natalia; Castillo, Laura; Figueroa, Giselle; Mächler, Andrea; Medrano, Diego; Patiño, Santiago...; Suarez, Daniela (2020). Antropología Xñ: Migración. Bogotá: LAAB/ACANT.

Blum, Susan (2019). Why Don't Anthropologists Care about Learning (or Education or School)? An Immodest Proposal for an Integrative Anthropology of Learning Whose Time Has Finally Come. American anthropologist, 121(3), 641-654. https://doi.org/10.1111/aman.13268

Bourdieu, Pierre; Passeron, Jean-Claude (2009). Los herederos. Los estudiantes y la cultura. Buenos Aires: Siglo XXI.

Bubandt, Nils; Otto, Ton (2010). Anthropology and the Predicaments of Holism. En Experiments in Holism: Theory and Practice in Contemporary Anthropology (pp. 1-15). London: Blackwell.

Buell, Rebeca; Burns, Samuel; Chen, Zhuo; Grabinsky, Lisa; Hurtado, Argelis; Stanton, Katherine...; White, Loren (2019). Reworking the History of Social Theory for 21st Century Anthropology: A Syllabus Project. Recuperado de https://footnotesblog.com/2019/02/15/ decanonizing-anthropology/comment-page-1/

Clifford, James (2005). Rearticulating Anthropology. En Unwrapping the Sacred Bundle: Reflections on the Disciplining of Anthropology (pp. 24-48), compilado por Daniel A. Segal; Sylvia J. Yanagisako. Duke: Duke University Press.

Diemberger, Hildegard; Hastrup, Kirsten; Schaffer, Simon; Kennel, Charles F.; Sneath, David; Bravo, Michael...; Bodenhorn, Barbara (2012). Communicating Climate Knowledge: Proxies, Processes, Politics. Source. Current Anthropology, 53(2), 226-244.

Durrani, Mariam (2019). Upsetting the Canon. Recuperado de http://www.anthropology-news. org/index.php/2019/04/08/upsetting-the-canon/

Eco, Umberto (1993). El lector modelo. En Lector in fábula. La cooperación interpretativa en el texto narrativo (pp. 73-93). Madrid: Lumen.

Eco, Umberto (2007). ¿De qué sirve el profesor? Recuperado de https://www.lanacion.com.ar/ opinion/de-que-sirve-el-profesor-nid910427 
Finkelstein, Maura (2019). What is a Classroom For? Teaching the Anthropology of Palestine. Teaching Tools. Fieldsights. Recuperado de https://culanth.org/fieldsights/what-is-aclassroom-for-teaching-the-anthropology-of-palestine

Gell, Alfred (1998). Art and agency. Oxford: Clarenton Press.

Goldstein, Donna (2016). Anthropological Pasts and Futures. En 'Thin Partitions': Bridging the Growing Divide between Cultural Anthropology and Archaeology (pp. 253-267), compilado por Joshua Englehardt; Ivy Rieger. Denver, CO: University Press of Colorado.

Graeber, David; Wengrow, David (2020). Cómo cambiar el curso de la historia humana, o almenos lo que ya pasó. Recuperado de https://www.elsaltodiario.com/el-rumor-de-las-multitudes/ como-cambiar-el-curso-de-la-historia-humana-o-al-menos-lo-que-ya-paso

Grimson, Alejandro (2016). Desafíos para las antropologías desde el sur. Intervenciones en estudios culturales, 3, 135-149.

Guarasci, Bridget; Moore, Amelia; Vaughn, Sarah (2018). Citation Matters: An Updated Reading List for a Progressive Environmental Anthropology. Recuperado de https:/culanth.org/ fieldsights/citation-matters-an-updated-reading-list-for-a-progressive-environmentalanthropology

Hastrup, Kirsten (2003). Desire and Deception: A Discussion of Gender, Knowledge and University Education. Arts \& Humanities in Higher Education, 2(3), 231-248. https://doi. org/10.1177/14740222030023002

Hastrup, Kirsten (2018). Collaborative Moments. Expanding the Anthropological Field through Cross-Disciplinary Practice. ETHNOS, 83(2), 316-334. https://doi.org/10.1080/0014184 4.2016.1270343

Hugh-Jones, Stephen (2018). Su riqueza es nuestra riqueza: perspectivas interculturales de objetos o gaheuni. En Objetos como testigos del contacto cultural. Perspectivas interculturales de la historia y del presente de las poblaciones indígenas del alto río Negro (Brasil/Colombia) (pp. 197-226), compilado por Michael Kraus; Ernst Halbmayer; Ingrid Kummels. Berlin: Gebr. Mann Verlag.

Ingold, Tim (2000). The Perception of the Environment. Essays on livelihood, dwelling and skill. London: Routledge.

Ingold, Tim (2003). Two Reflections on Ecological Knowledge. En Nature Knowledge: Education, Cognition, Identity (pp. 301-311), compilado por Glauco Sanga; Gherardo Ortalli. New York: Berghahn.

Ingold, Tim (2013). Making. Anthropology, archeology, art. New York: Routledge. 
Ingold, Tim (2015). Desde la complementariedad a la obviación: sobre la disolución de los límites entre la antropología social, biológica, arqueología y psicología. AVÁ, 26, 12-51.

Ingold, Tim (2018). Anthropology and/as education. New York: Routledge.

Jimeno, Myriam; Arias, David (2011). La enseñanza de antropólogos en Colombia: una antropología ciudadana. ALTERIDADES, 21(41), 27-44.

Kawa, Nicholas (2018). How Academic Hierarchy Shapes the Distribution of Precarity. Recuperado de https://culanth.org/fieldsights/how-academic-hierarchy-shapes-the-distribution-ofprecarity

Khoshman, Afaf (2018). How Teachers Can Use Anthropology in Classrooms. Recuperado de https://www.al-fanarmedia.org/2018/08/how-teachers-can-use-anthropology-inclassrooms/

La Silla Vacía (4 de marzo de 2019). ¿Votamos a ciegas en elecciones? [Video]. Recuperado de: https://www.youtube.com/watch?v=GOgd1_M_XOO

Latour, Bruno (2005). Reassembling the Social. An Introduction to Actor-Network-Theory. New York: Oxford University Press.

Lins, Gustavo; Escobar, Arturo (2008). Antropologías del mundo: transformaciones disciplinarias dentro de sistemas de poder. En Antropologías del mundo. Transformaciones disciplinarias dentro de sistemas de poder (pp. 25-54). México: Envión.

Malafouris, Lambros; Renfrew, Colin (2010). The Cognitive Life of Things: Archaeology, Material Engagement and the Extended Mind. En The Cognitive Life of Things: Recasting the Boundaries of the Mind (pp. 1-12). London: Mcdonald Institute Monographs.

Mariner, Kathryn (2018). Teaching as Activism: The Educational Intervention Project as a Tool of Transformation. Recuperado de https://culanth.org/fieldsights/teaching-as-activism-theeducational-intervention-project-as-a-tool-of-transformation

Mauksch, Stefanie (2018). Envisioning Theory: An Anthropological Teaching Experiment, Part One. Recuperado de https://culanth.org/fieldsights/envisioning-theory-an-anthropologicalteaching-experiment-part-one

McLean, Stuart (2017). Fictionalizing Anthropology Encounters and Fabulations at the Edges of the Human. Minneapolis: University of Minnesota Press.

Ojeda, Diana; Guerra, Pablo; Aguirre, Camilo; Díaz, Henry (2016). Caminos condenados. Bogotá: Laguna.

Ojeda, Diana; Serna, Sonia; Arias, Julio (comps.), (2020). Recetario de sabores lejanos. Bogotá: Laguna. 
Parikh, Anar (2018). Teaching Podcasts in the Anthropology Classroom. Recuperado de https:// culanth.org/fieldsights/teaching-podcasts-in-the-anthropology-classroom

Pedersen, Morten Axel (2007). Talismans of Thought: Shamanist Ontologies and Extended Cognition in Northern Mongolia. En Thinking through things. Theorising artefacts ethnographically (pp.141-166), compilado por Amiria Henare; Martin Holbraad; Sari Wastell. New York: Routledge.

Pezzatti, María Laura (2018). Aprendizaje de reglas aritméticas. En Aprendizaje de reglas matemáticas (pp. 118-132). Buenos Aires: Universidad de Buenos Aires.

Restrepo, Eduardo (2018). El espectro Boasiano de las "cuatro ramas": la arqueología y el sentido común disciplinario en Colombia. En Diálogos con la antropología latinoamericana (pp. 109-130), editado por Pablo Gatty; Lydia de Souza. Montevideo: ALA.

Salovaara, Isabel (2019). Teaching Infrastructures: A Conversation with Gabrielle Hecht. Teaching Tools. Fieldsights. Recuperado de https://culanth.org/fieldsights/teachinginfrastructures-a-conversation-with-gabrielle-hecht

Sarikoudi, Georgia (2019). What Socio-Cultural Anthropology can do for Education? Recuperado dehttps://www.teachinganthropology.org/2019/11/02/what-socio-cultural-anthropologycan-do-for-education/

Seaver, Nick (2018). How to Pay Attention. Recuperado de http://somatosphere.net/2018/ how-to-pay-attention.html/

Severi, Carlo (2012). The Arts of Memory: Comparative Perspectives on a Mental Artifact. HAU: Journal of Ethnographic Theory, 2(2), 451-485. https://doi.org/10.14318/hau2.2.025

Shankar, Arjun; Zurn, Perry (2020). Conclusion: On Teaching Curiosity. En Curiosity studies: A newecology ofknowledge. Minneapolis: University of Minnesota Press. Recuperado de https:// manifold.umn.edu/read/64316c7b-6f7a-445f-8922-47a5f61ee512/section/672957b4788b-40c5-a747-f66544b641fe\#conc

Willeslev, Rane; Suhr, Christian (2013). Introduction. Montage as an Amplifier of Invisibility. En Trasncultural montaje (pp. 1-15). New York: Berghahn. 